\title{
Prometeu contra Hermes: 0 lugar do design no imaginário contemporâneo
}

\section{Marcos Beccari}

Doutor, Universidade Federal do Paraná, Curitiba, PR, Brasil

contato@marcosbeccari.com

\author{
Alberto Filipe Araújo \\ Doutor, Universidade do Minho, Braga, Portugal \\ afaraujo@ie.uminho.pt \\ Rogério de Almeida \\ Doutor, Universidade de São Paulo, São Paulo, SP, Brasil \\ rogerioa@usp.br
}

\section{Resumo}

Este artigo propõe uma reflexão sobre o imaginário contemporâneo, tomando o design como vetor central e duas figuras míticas, Hermes e Prometeu, como coordenadas principais. De início, tecemos algumas considerações acerca das bases teóricas que amparam a abordagem aqui proposta e, em seguida, indicamos o modo como as figuras de Prometeu e Hermes conduzem boa parte da dinâmica sociocultural. Na sequência, analisamos o paradigma pós-prometeico que Bruno Latour identifica a partir de cinco conotações do termo design. Concluímos, por fim, que os mitos de Hermes e Prometeu se encontram implicados um no outro e que o design expressa, no imaginário contemporâneo, essa correlação.

\section{Palavras-chave}

Imaginário contemporâneo. Prometeu. Hermes. Design.

\section{Introdução}

A premente tarefa de nos tornarmos contemporâneos de nosso tempo (e de outros) implica compreender as coordenadas simultaneamente prometeicas e hermesianas que 
atravessam nossos pensamentos. 0 mito de Prometeu, aquele que pensa por antecipação (pro-manthéin), persiste em se reatualizar de modo ora contraposto, ora adjacente ao mito de Hermes, aquele que relativiza os contrários e que mostra que o contraditório e o paradoxal são a expressão adequada do mundo humano. Nesse terreno plural, em que imperativos dicotômicos e apaziguadores convivem com aporias e oximoros diversos, encontramo-nos enredados pelo design, noção que ganha força como expressão e forma da sensibilidade estética de homens e mulheres.

Mais do que uma atividade ou um produto designado a sanar demandas sociais específicas, design é aqui compreendido como um modo (não estrito aos designers) de produzir imagens, aparências e formas de olhar. Mais precisamente, o design pode ser lido como "articulação simbólica": um constante processo de mediação e (re)criação de narrativas que se abrem a novas interpretações, processo este do qual se vale o olhar contemporâneo para compreender o mundo e atuar nele (BECCARI, 2016). Nesse sentido, vivemos, aprendemos, trabalhamos, nos relacionamos e nos imaginamos em meio a narrativas e imagens produzidas "tecnicamente" (FLUSSER, 2008) que, por sua vez, nos informam e nos convocam a interpretar o mundo em um misto de diversão, vigilância, fantasia, ativismo, voyeurismo etc.

Parece-nos, com efeito, que o design se encarrega de articular uma parte considerável das mediações simbólicas contemporâneas. Nosso desejo de investigação, no entanto, não mira o design e suas dinâmicas simbólicas, mas certos vetores simbólicos que agenciam a atual circulação de imagens e narrativas. Dito de outro modo, colocamo-nos a tarefa de refletir sobre a "localização" do design no imaginário contemporâneo, tomando duas figuras míticas, Hermes e Prometeu, como coordenadas principais.

Em convergência com tais coordenadas, discutimos e interpretamos o artigo Um Prometeu cauteloso?, no qual Bruno Latour (2014) identifica um paradigma pós-prometeico a partir de cinco conotações do termo design. Antes disso, porém, será necessário tecermos algumas considerações acerca das bases que amparam a abordagem aqui proposta e, em seguida, esboçarmos um panorama da "bacia semântica" (DURAND, 1996, p. 85) que, imiscuída entre Hermes e Prometeu, tem animado a dinâmica sociocultural contemporânea.

Abertura às diferenças, dicotomia entre consciência e alienação, verdades insuficientes, igualdade de direitos, generalizações e dissonâncias são questões que marcam o mundo contemporâneo e para as quais não pretendemos oferecer respostas, mas uma via de interpretação pautada no pressuposto de que o mundo humano é fundamentalmente 
organizado pelo imaginário - registro que faz circular não apenas imagens, símbolos e mitos, mas também sentidos, pensamentos, razões etc. Nesse ínterim, a noção de design se desvela como um modo de apropriação do "mundo do texto", nos termos de Ricoeur (2008, p. 68), que é a aventura de ler e reescrever o mundo (e o ser-no-mundo) no espelho das palavras, símbolos e imagens.

\section{0 imaginário e sua pronúncia mítica}

Em sua acepção mais difundida, "mito" significa uma representação coletiva que relata uma explicação do mundo (BRANDÃO, 1986). Tal explicação, não obstante, se vale menos de significados ou enunciados e mais de uma lógica própria: simbólica, imagética, poética (FERREIRA-SANTOS; ALMEIDA, 2012). Em outros termos, trata-se de um modo de conhecimento que opera narrativamente. Pela criação, transmissão, apropriação e interpretação de imagens (como as que circulam, por exemplo, em obras literárias ou cinematográficas), os mitos organizam a consciência que uma dada cultura tem de si própria e da realidade como um todo, balizando assim os valores, as relações, as contradições, enfim, os contornos de cada sociedade.

Contudo, no amplo contexto da iconoclastia ocidental (DURAND, 2010), o mito foi relegado a um plano inferior em relação ao conhecimento racional, como se a imaginação turvasse a compreensão humana. A intensidade estruturante do mito, do símbolo e do imaginário ${ }^{1}$ como um todo foi especialmente resgatada por Gilbert Durand, discípulo de Gaston Bachelard. Suas pesquisas atestam que "[...] o conceito é o rascunho da imagem." (FERREIRA-SANTOS; ALMEIDA, 2012, p. 31), pois na imagem associam-se o racional e o sensível, não estando o que é tido por irracional apartado da razão, mas ambos amalgamados no e pelo imaginário.

É nesse sentido que o imaginário organiza o real, o que não implica entre um e outro uma relação causal ou de oposição, uma vez que tais relações se expressam justamente no imaginário. Nessa visada epistemológica, os mitos são simultaneamente produtos e produtores dos sentidos mediados por meio de símbolos que, por sua vez, tendem a se organizar em narrativas (DURAND, 1997), como as que se encontram na pintura, no poema, nas palavras de ordem, num conjunto de leis, em uma melodia musical etc. Inversamente,

\footnotetext{
1 “[...] o imaginário - ou seja, o conjunto das imagens e relações de imagens que constitui o capital pensado do homo sapiens aparece-nos como o grande denominador fundamental onde se vêm encontrar todas as criações do pensamento humano." (DURAND, 1997, p. 18).
} 
tais narrativas, para além de seu sentido concreto, imediato, conformado pelas contingências socioculturais ou biográficas, guardam um sentido figurado, simbólico, identificável através do reconhecimento dos mitemas, isto é, unidades significantes que constituem a "recorrência simbólica" (FERREIRA-SANTOS, ALMEIDA, 2012, p. 76) presente nos mitos.

Em termos metodológicos, Durand $(1983,1992,1998)$ propôs duas modalidades de estudo dos mitos: a mitocrítica e a mitanálise. Enquanto a primeira consiste no estudo focado em um objeto ou conjunto de objetos (como relatos ou obras literárias), com o intuito de depreender os mitos que estão na base de seu universo simbólico, a segunda se volta para a reincidência dos mitemas que atuam em uma dada sociedade de um determinado momento histórico, de modo a compreender simbolicamente sua paisagem cultural e seu horizonte de valores. Se “[...] os 'últimos passos' da mitocrítica caminham progressivamente para uma mitanálise e mesmo para uma filosofia [...] da história e da cultura." (DURAND, 1998, p. 258), o presente estudo aponta, dando continuidade às mitocríticas/mitanálises anteriormente desenvolvidas por seus autores ${ }^{2}$, para um caminho possível de mitanálise sobre a cena (ou design) contemporânea.

Cumpre também observarmos que, em se tratando de mitanálise, as incidências e atualizações míticas geralmente partem de uma "latência" e se direcionam a uma explicitação (DURAND, 1983). Mais precisamente, trata-se da concatenação de "bacias semânticas" (metáfora fluvial adotada posteriormente por Durand), movimento em que um mito desmitologiza-se para que outro se remitologize. Tais processos "[...] escalonam-se num movimento em espiral - sob as 'margens' filosóficas de uma bacia semântica formam-se já 'escoamentos' de outra bacia e, sob 'os deltas e os meandros', determina-se a 'separação das águas' do rio que está para vir [...]" (DURAND, 1998, p. 165).

Nesse sentido, o século XX (principalmente após a II Guerra) teria visto renascer, segundo Durand (1992), o mito de Hermes a partir do esgotamento do mito unitário de Prometeu e de seu contraponto, Dioniso. Esse ressurgimento hermesiano teria se manifestado inicialmente no seio das vanguardas artísticas - ainda que, consideradas isoladamente, muitas reproduzissem valores prometeicos e dionisíacos. É o caso do futurismo italiano, cujo furor destrutivo era ainda um prolongamento das configurações

\footnotetext{
2 Alberto Filipe Araújo (2012) descreveu as atualizações do mito de Fausto por meio de obras literárias e cinematográficas, ao passo que Rogério de Almeida (2011) delineou o modo pelo qual Hermes se lastreia pela obra de Fernando Pessoa e seus heterônimos; posteriormente, Almeida (2014) identificou a confluência entre Prometeu, Dioniso, Hermes e Fausto nas tensões da contemporaneidade; por sua vez, Araújo (ARAÚJO; GOMES; ALMEIDA, 2014, p. 103-139) investigou a simbólica do labirinto (mito de Teseu), relacionando-a com a metáfora do segredo no imaginário educacional.
} 
prometeicas; ou, no polo oposto, do impressionismo, que valorizava a subjetividade transformadora do olhar, de modo viscoso e confusional, características dionisíacas. A recusa prometeica teve que passar, de modo geral, pelo mitema órfico do fracasso/decadência, como vemos em Charles Baudelaire, André Gide e Herman Hesse. A remitologização de Hermes, então, teria finalmente se consolidado, por exemplo, na obra de Proust (DURAND, 1992), cuja escrita labiríntica expressa tanto a inexorabilidade quanto a reversibilidade do tempo, transformando-o em destino que assume as alteridades e os contrários.

Não obstante, o que nos leva a retomar, no presente artigo, a passagem de Prometeu a Hermes é a suspeita de que não se trata exatamente de uma transição, ao menos no sentido de inflexão ou esgotamento. Para iniciar nosso inquérito, vale atentarmos brevemente ao pensamento órfico, que teria motivado a inflexão prometeica e que expressa a busca subterrânea (gnose) de revelações como forma de ampliar o autoconhecimento. "Orfismo" designa um movimento religioso iniciado por volta do século VI a.C., formado por comunidades fechadas que celebravam um culto especial de Dioniso e consideravam o poeta trácio Orfeu seu fundador. Na perspectiva órfica, haveria no ser humano um elemento divino, um dáimon, que constitui o nosso eu profundo, a psyche. Essa palavra adquire então a semântica de "alma", como substância que se contrapõe, preexiste e sobrevive ao corpo (REALE, 2002).

Ora, destaca-se aqui de uma reviravolta semântica. Sabe-se que na Ilíada e na Odisséia, Homero se referia à psyche como uma espécie de "larva invisível": um resíduo que abandona o ser humano em seu último sopro, saindo pela boca ou por um ferimento e indo embora rumo ao Hades, onde permanece como uma sombra do defunto, num estado desprovido de consciência e à mercê do esquecimento (WILLIAMS, 2008). No registro homérico, com efeito, aquilo que somos não é a psyche, e sim o corpo visível, mesmo enquanto cadáver. Com o orfismo, porém, surge uma nova interpretação da natureza da psyche: agora ela aparece presa ao corpo, como numa prisão, por causa de uma culpa originária que deve ser extirpada com "purificações" apropriadas. Os órficos estavam convencidos de que, depois da morte do corpo, suas almas seriam julgadas, de modo que somente aquelas que haviam se purificado totalmente voltariam a viver com os deuses.

0 que se seguiu de tal inflexão semântica, sobretudo no âmbito filosófico, não sinalizou um esvaziamento do mito prometeico. Pelo contrário, vimos a formulação socrática do conceito de alma, como uma identidade única e em acordo com ela mesma, que 
depois será cindida por Platão (e depois por Descartes etc.). De maneira análoga, o pensamento contemporâneo pode até estar desconfiado dos preceitos prometeicos, mas continua a jogar com eles, por mais que seus valores se fragilizem e se contradigam. Ao mesmo tempo, em meio a tantas condutas díspares e inflexíveis, instaura-se um jogo contínuo de identidades flutuantes, intercambiáveis, múltiplas. Estamos diante, portanto, de uma dupla intimação: a prometeica, que nos solicita uma síntese e uma posição bem definida entre os polos contraditórios; e a hermesiana, que requer uma conciliação entre esses polos por meio de sua coincidência.

\section{As promessas de Prometeu}

Na mitologia grega, Prometeu é um titã conhecido por ter roubado o fogo divino para entregá-lo aos humanos (BRANDÃO, 1992). Como punição, Zeus teria ordenado Hefesto que o acorrentasse no cume do monte Cáucaso, onde todos os dias uma águia (ou corvo) dilacerasse seu fígado, que não cessa de se recompor. Aos humanos, a punição de Zeus consistiu em Pandora, a primeira mulher, modelada por Hefesto e animada pelos deuses, portadora do vaso (ou jarro) que, ao ser aberto, espalha os males da humanidade, restando em seu interior somente a esperança. 0 mito de Prometeu, assim, carrega o mitema do fogo divino e sua promessa de progresso, bem como o mitema da transgressão à ordem divina (não só contra Zeus, mas também contra Hermes), donde deriva a conduta prometeica de dominar, subjugar e transformar tecnicamente a natureza.

0 mito consta em diversas fontes antigas, em especial na Teogonia (versos 507 a 616) e em Os trabalhos e os dias (versos 42 a 105), ambos de Hesíodo (1981), e em Prometeu acorrentado, de Ésquilo (ÉSQUILO; SÓFOCLES; EURÍPEDES, 1953). Entre os poemas de Hesíodo e a tragédia de Ésquilo, contudo, há uma nítida inversão de tratamento. De um lado, Prometeu é retratado por Homero como sendo "culpado" de todos os males (em associação direta com Pandora), reforçando a soberania de Zeus, o mais justo e mais sábio dos deuses. De outro, o Prometeu de Ésquilo é o benfeitor da humanidade, e todos os personagens do enredo (com exceção de Hermes) denunciam Zeus como um tirano cruel e perverso.

Ao longo dos séculos, a ambiguidade em torno de Prometeu foi reatualizada por diversos autores. Em 1776, por exemplo, Goethe (1979) publicou um pequeno poema intitulado Prometheus, onde o titã é elogiado por ter se negado a venerar os deuses; em sua fase mais madura, porém, Goethe parece mudar de opinião com o poema Grenzen der Menschheit (Limite da humanidade), onde ele passa a elogiar os deuses e aponta em 
Prometeu o limite das capacidades humanas. Essa variação semântica serve-nos para reforçar a dinâmica do mito enquanto forma de conhecimento: dado de modo narrativo e simbólico, todo mito opera por meio de uma lógica polivalente que incorpora dadas sensibilidades em cada contexto. Assim, o mito não explica, mas aciona sentidos possíveis para as diversas dimensões da experiência: psicológica, social, existencial etc.

André Dabezies, ao historicizar a ocorrência do mito de Fausto na Literatura, aponta sua ligação, sob a influência romântica do final do século XIX, com Prometeu. Quando Fausto passa a ser, diferentemente de sua configuração inicial no século XVI, “[...] a figura ideal da humanidade moderna que aspira à liberdade, à ação, ao progresso [...]" (DABEZIES, 1998, p. 337), algumas linhas de força prometeicas ganham destaque: o domínio sobre a natureza, a hybris desafiadora dos limites humanos, a crença na autonomia do homem moderno, a busca pela identidade única e pelo saber unificado, o impulso de criar algo a qualquer custo e até em sacrifício de si mesmo.

É nesses termos que o mito de Prometeu parece ser amplamente entendido, sendo também frequentemente associado a noções como "vontade", "liberdade", "ambição" e mesmo "megalomania". Entretanto, não podemos perder de vista a ambiguidade que é inerente aos mitos; caso contrário, corremos o risco de fabricar uma versão caricata. Mostra-se útil, nesse ínterim, a identificação de alguns ideologemas (ARAÚJO; GOMES; ALMEIDA, 2014) prometeicos, isto é, aspectos míticos transmutados em significantes ideológicos (conceitos, princípios ou imperativos) que circulam em dado contexto histórico sociocultural. Podemos partir, então, de três conotações etimológicas extraídas por Dougherty (2006) da palavra "Prometeu": (1) antevisão, do grego antigo pro ("antes") e manthano ("aprender"); (2) ladrão ou roubo, seguindo a raiz proto-indo-europeia de pramath ("roubar") ou pramathyus ("ladrão"); (3) fogo, do sânscrito védico pramantha, que designa uma ferramenta usada para se fazer fogo.

Para pensarmos em tais conotações enquanto ideologemas prometeicos, podemos cruzá-las, por exemplo, com as ideologias "iluminista" e "romântica", conforme as descreve Bloor (2009). A primeira possui quatro características principais: (1) é individualista e atomista, como indicam as famosas teorias do contrato social; (2) pressupõe leis universais que permitem explicar, prever e "dominar" o mundo concreto; (3) privilegia o dedutivismo abstrato, isto é, a dedução lógica por meio de princípios gerais; (4) costuma ser prescritiva e moralizadora no âmbito político. A ideologia romântica, por sua vez, apresenta outras quatro características: (1) pressupõe uma natureza transcendente, como sugerem os termos 
"espírito", "tradição", "identidade nacional" etc.; (2) é holística, pois pressupõe que o "todo" (ou o contexto) transcende a soma das partes; (3) encara o concreto e o histórico como aspectos mais importantes que o abstrato e o universal; (4) considera que valores transcendentes são esvaziados pelo racionalismo sistemático e pelo atomismo.

A descrição das ideologias, como se pode observar, é demasiado genérica, mas suficiente para mostrar algumas sinuosidades dos ideologemas prometeicos. A antevisão, por exemplo, ampara a valoração iluminista que considera a relação "contratual" (previamente estabelecida) entre indivíduos como melhor do que uma relação "orgânica". Já a figura do ladrão/roubo ganha contornos tanto iluministas quanto românticos: de um lado, na ideia de Adam Smith (1983) acerca de uma "mão invisível" natural das sociedades; de outro, na proposta de Thomas Carlyle (1970), que encara a relação social baseada no dinheiro como falsa e alienante. Por fim, o mitema do fogo (como um bem precioso) se atualiza tanto no utilitarismo inglês, sobretudo em Stuart Mill (2000), que define o bem como a maximização do prazer para o maior número de pessoas, quanto em William Blake (SANTOS, 2009), para quem a elevação espiritual não resulta dos cálculos da razão.

Traçar esquematicamente as dualidades prometeicas a partir de exemplos históricos não parece ser, portanto, uma tarefa particularmente difícil. 0 mais difícil é conseguir apreender com clareza a complexidade prometeica mediante outras lógicas que disputam pelo protagonismo das múltiplas tramas que são encenadas no palco contemporâneo. Não é incomum, afinal, que um mesmo mito-matriz sirva para orientar ideologemas opostos, tanto quanto o inverso, que alguns ideologemas aparentemente opostos se recombinem em novas formas de atualização mítica. Esse próprio movimento de retomada e hibridização de determinadas figuras organizadoras do tecido societal já indica, segundo Durand (1992), o predomínio de Hermes nas atuais bacias semânticas. Nossa suspeita, então, não é em relação à presença hermesiana (que nos parece bem visível e suficientemente assimilada), mas em relação ao suposto esgotamento do mito prometeico, que aparentemente perdura, ainda que reconfigurado e por vezes relegado a um espaço de coadjuvante.

\section{Prometeu contra Hermes: coincidentia oppositorum?}

Avançando em sua leitura, Durand (1979,) identificou a coexistência de três mitos em nossa cultura ocidental. 0 primeiro seria Prometeu, que nortearia a esfera do "instituído", ou seja, de certas instituições que dependem de valores prometeicos (como controle, disciplina e permanência) para continuar a operar. 0 segundo é Dioniso, infiltrado 
no discurso decadentista dos mass media, na dispersão do indivíduo inclinado ao dispêndio, no crescimento de esoterismos etc. ${ }^{3} \mathrm{E}$ o último e mais recente seria Hermes, que rege a ampla coexistência de condutas e expressões contrárias entre si - como, por exemplo, a de um individualismo patente e notório com expressões de experiências coletivas, em que o grupo se sobrepõe ao indivíduo, ou ainda as estratégias geopolíticas de unificação e de dissolução, que convivem e se alternam entre os países.

Enquanto a passagem de Dioniso teria sido marcada pelo desregramento e pela negação dos valores que reinaram sob o auspício prometeico, a lógica hermesiana que lhe teria procedido passa a exaltar a capacidade de pensar os contrários sem apagá-los. Não se trata de síntese ou equilíbrio, mas de uma tensão sempre insolúvel entre diferenças, as quais podem até ceder a conciliações pontuais, sem, no entanto, se anularem ou se ajustarem a qualquer tentativa de homogeneização.

Hermes, "arauto dos imortais" (HESÍODO, 1981, p. 156), é o deus mediador, intérprete da vontade dos deuses e condutor de almas (psicopompo). Hermes não só é responsável pela pluralidade como é ele próprio plural, como atestam seus correlatos: Mercúrio romano, Thot egípcio, Hermes Trimegisto alquímico, Wotan germânico - além de uma série de outros "disfarces", como o profeta islâmico Idris, o São Francisco cristão, o Virgílio de Dante, o boto brasileiro etc. Conhecido como puer aeternus - ao mesmo tempo puer (criança) e senex (velho) -, Hermes é também sermo (discurso, língua) e ratio (razão, inteligência). Logo após nascer, fez-se ladrão do rebanho de seu irmão Apolo, como quem comercializa a lira que acabara de inventar; como mediador, atua como intermediário de Zeus da libertação de Io transformada em bezerra, assim como no episódio das três deusas (Afrodite, Atena e Hera) e Páris; é também o psicagogo que guia Héracles na descida aos infernos, que inicia Perseu e se constitui como civilizador, (trans)portando saberes comerciais, diplomáticos, militares etc.

A mitanálise durandiana nos mostra Hermes ressurgindo no século XX como angelos (mensageiro), deus da comunicação e das diferenças entre os comunicantes, portanto deus das encruzilhadas, divindade dos limites, enfim, arquétipo do sentido de toda linguagem (DURAND, 1979). Tal guinada hermesiana lançaria luz, em contraparte, sobre o mito prometeico que encampou boa parte do território da modernidade. Nesse sentido, Hall (2000) argumenta que, sem que se tenha um nítido rompimento com a modernidade, o

\footnotetext{
3 Para um estudo mais atento sobre a incidência de Dioniso como força estruturante nas sociedades contemporâneas ver Nietzsche (2007), Maffesoli (2005) e Almeida (2014).
} 
sujeito pós-moderno passou a aceitar múltiplas identidades e a se identificar com situações, pessoas e valores contraditórios. Parece não haver dúvidas, pois, sobre a predominância mítica de Hermes nos valores socioculturais que circulam na atualidade.

A questão a ser levantada, então, repousa mais no horizonte complexo das sinuosidades hermesianas, ainda que o mito já englobe todos os oximoros possíveis. Significa que, diferentemente da maneira como tratamos da ambiguidade prometeica, não nos parece adequado rastrear alguns ideologemas hermesianos, uma vez que é próprio de Hermes fazer coincidir polos contraditórios. Uma estratégia possível, então, consiste em explorar a relação, direta ou indireta, entre Hermes e Prometeu. Por exemplo, a inflexão prometeica que supostamente teria propiciado o renascimento hermesiano remete-nos à imagem de um episódio expressivo: no pior momento de Prometeu, em que mesmo preso ele se mostra inflexível, arrogante e orgulhoso, Hermes o acusa de ter a "razão conturbada" (ÉSQUILO; SÓFOCLES; EURÍPEDES, 1953, p. 37-41). A princípio, essa razão conturbada parece servir para indicar uma diferença entre humanos e deuses (mesmo Prometeu não sendo humano, ele se posiciona ao lado da humanidade). No entanto, essa distinção divina somente faz sentido em contraposição à arrogância do titã. De modo análogo, a virada hermesiana na trama contemporânea talvez dependa diretamente da precedência prometeica - Hermes só é visível em relação a Prometeu.

Voltando aos mitos, sabemos que Prometeu consegue escapar de seu castigo eterno: Héracles (o mesmo que outrora foi guiado por Hermes) mata a águia e liberta o titã. Mas Zeus só libertaria Prometeu se algum imortal abrisse mão de sua imortalidade. 0 acordo hermesiano envolve Quíron, centauro imortal (filho de Cronos) que preferiu morrer em vez de continuar com uma ferida (acidentalmente aberta por uma flecha de Héracles) sangrando para sempre (BRANDÃO, 1992,). É notável aqui o mitema prometeico da "ferida" como possibilidade de renovação, ou seja, o aprendizado que só é possível através do sofrimento. Porém, sob a perspectiva hermesiana pela qual os opostos sempre coincidem, destaca-se a alcunha de Quíron como "grande curandeiro". Ou seja, o centauro curador é quem de fato se "sacrifica" (por si e pelos outros), curando suas próprias dores e fazendo cessar o sofrimento de Prometeu.

Logo, a noção prometeica de "sacrifício" depende diretamente da contraparte da cura, de modo que toda cisão pressupõe e propicia a integração, a justaposição. Se é verdade, portanto, que a lógica hermesiana só faz sentido em relação à prometeica (e sua "razão conturbada"), também é verdade que, inversamente, a lógica prometeica só faz 
sentido em relação à hermesiana. Afinal, quando vemos em certos discursos a revalorização de aspectos prometeicos como controle, disciplina, ordem, unidade e superação, o que se verifica é justamente uma reação ao rosto de Hermes, à explicitação das diferenças, das alteridades, das contradições e paradoxos. E, no sentido inverso, na medida em que o protagonismo hermesiano obtém repercussão, como através da valorização das minorias e das diferenças individuais/culturais, mais se segmentam os impulsos prometeicos de etnocentrismo, meritocracia, impunidade, intolerância etc.

É nesse registro de adjacências e divergências entre Hermes e Prometeu que se conjugam os impasses contemporâneos: novos modos de inclusão social que convivem com novos modos de exclusão, novos direitos conquistados que não interferem no descaso dos governantes e do povo que os elegem, regimes democráticos que favorecem tendências hegemônicas, palavras de ordem que convivem com relativismos, culturas locais que enaltecem culturas globais, utopias igualitárias que se confundem com distopias fatalistas, populismo que se confunde com tecnocracia etc. Assim, os vários setores em transformação, quando vistos em conjunto, permitem assinalar com abrangência as linhas de força postas em jogo, que dividem e fazem coincidir vozes hermesianas e (pós)prometeicas.

\section{A ressignificação pós-prometeica do design}

Em seu artigo Um prometeu cauteloso? Latour (2014) vale-se de algumas conotações do termo design para pensar sobre os atuais modos de encarar a atuação humana sobre o mundo. É fácil observar, logo de início, que Latour, apesar de relacionar frequentemente a noção "prometeica" aos aspectos do pensamento moderno, evita recorrer à expressão "pósmoderno" - uma vez que considera, como indica o título de um de seus livros mais famosos, que jamais fomos modernos. Ele prefere se referir, aqui, a uma teoria "pós-prometeica" da ação. Antes de entrar nessa questão, o filósofo explica como a noção de design lhe foi apresentada pela primeira vez: um revestimento "estético", definido por questões de gosto e de moda, para aquilo que foi projetado "seriamente", isto é, a funcionalidade mecânica, os atributos materiais, as questões econômicas. Em outras palavras, design como um "verniz" sem o qual uma cadeira, um livro, um carro ou um laptop permaneceria desajeitado, duro ou cru demais.

Tal perspectiva faz alusão, embora de modo simplificado ou mesmo ingênuo, ao paradigma moderno do design, expresso por imperativos como "a forma segue a função" (SULLIVAN, 1988, p. 208) ou "adequação ao propósito" (GROPIUS, 2004, p. 29). Por esse 
viés, o design seria constituído tanto de elementos superficiais e efêmeros, geralmente atrelados a questões de ordem estética, quanto (e principalmente) de elementos eficazes e importantes, que seriam os mecanismos "duros" que de fato fazem as coisas funcionar. Todavia, Latour (2014, p. 3) argumenta que o termo design se expandiu de tal maneira que hoje pode servir para indicar "cidades, paisagens, nações, culturas, corpos, genes [...] e [a] própria natureza". A conotação moderna de design, portanto, estaria cada vez mais perdendo lugar para uma visão ampla do design como algo pertinente e intrínseco a tudo que nos cerca.

Não apenas a natureza como o lado de fora da ação humana desapareceu (isso já se tornou senso comum); não apenas "natural" se tornou um sinônimo de "cuidadosamente administrado", "habilidosamente encenado", "artificialmente mantido", "inteligentemente elaborado" (isso é especialmente válido para os assim chamados "parques naturais" ou "alimentos orgânicos"); mas também a própria ideia de que usar o conhecimento dos cientistas e engenheiros para lidar com uma questão é necessariamente o mesmo que recorrer às inquestionáveis leis da natureza está se tornando obsoleta (LATOUR, 2014, p. 16).

O que o autor sublinha, com efeito, não é tanto uma mudança no entendimento do que significa design, e sim uma mudança na maneira como lidamos com objetos e ações de maneira geral - o que, por sua vez, tende a ressignificar a noção de design. Mais precisamente, a passagem do que se costuma chamar "modernidade" para o que se costuma denominar "pós-modernidade" é encarada por Latour (2014) como a transição de um referencial prometeico, calcado na pretensão universalista, para um referencial pósprometeico, que o filósofo caracteriza a partir de cinco conotações do termo design na atualidade. Vamos a elas. A primeira diz respeito ao caráter simples ou modesto do termo, em comparação com palavras como "projeto" ou "planejamento", que presumem método, problema e objetivo pretensamente edificados. A segunda está ligada a uma "atenção aos detalhes", em oposição à ambição prometeica das reformas e revoluções, que tendem a relegar muitas coisas à esfera dos "detalhes pouco importantes". A terceira é a íntima ligação do design com a dimensão estética que, não sendo mais considerada meramente efêmera e inútil, se imiscui aos demais registros. A quarta se refere ao caráter "adaptativo" do design, em oposição à lógica de "criação a partir do nada" do referencial moderno/prometeico. A quinta, por fim, é a que considera o design como um exercício criativo de (re)valoração moral, e não uma representação, confirmação ou recusa de princípios éticos universais. 
É nesse sentido que vejo a proliferação do termo design como um claro substituto para revolução ou modernização. [...] Fazer design é o antídoto para os atos de fundar, colonizar, estabelecer ou romper com o passado. É o antídoto para a arrogância e para a busca de certezas absolutas, começos absolutos e de desvios radicais (LATOUR, 2014, p. 8).

A partir de então, Latour (2014) faz questão de frisar que o modo pós-prometeico de ação (ou seja, um fazer orientado pelo design) está muito distante da crise ou desnorteamento que se costuma associar ao "pós-modernismo". Em vez disso, o viés pósprometeico reside na explicitação da esfera hermenêutica que circunscreve a atuação humana no mundo contemporâneo: uma atuação passiva de interpretações múltiplas, e não mais de um crivo unitário tido como verdadeiro e absoluto. Nesse sentido, não é que o referencial moderno/prometeico tenha se arruinado, mas apenas que seu próprio aspecto de "referencial" tornou-se mais visível, desnaturalizado, assim como os valores que ele carrega. É um reconhecimento, em suma, que remete aos dizeres de Nietzsche (2005, aforismo 108): "Não existem fenômenos morais, apenas uma interpretação moral dos fenômenos...".

Ao passo que Latour (2014) está mais preocupado com o âmbito social da atuação humana, Portugal (2016) mostra como a teoria pós-prometeica da ação pode ser fecunda para refletir sobre questões relacionadas à agência humana no âmbito subjetivo, como as noções de vontade, liberdade e criação. 0 autor se ampara em Nietzsche (2005) - sobretudo em sua genealogia - para propor três categorias: sujeito pré-prometeico, sujeito prometeico e sujeito pós-prometeico. A primeira faz referência ao modo metafísico tradicional de entender o sujeito, cuja liberdade depende da adesão a uma ordem cósmica ou divina. 0 sujeito prometeico, por sua vez, pensa o "livre-arbítrio" no limiar entre uma causalidade empírica e uma necessidade transcendente. Por fim, o sujeito pós-prometeico abandona a correlação entre moral, verdade e universalidade e passa a pensar na vontade como uma força imanente, à qual não faz sentido aplicar categorias como liberdade ou necessidade.

Assim, a pergunta sobre a liberdade da vontade e da agência do sujeito é remetida não mais à verdade ou a um Bem universal, mas às formas de criação de tais noções. 0 sujeito pós-prometeico aparece, assim, como um criador. Mas não um criador prometeico, que traria para o mundo algo de uma esfera transcendental, e sim um designer, que articula, na imanência, valores e aparências. (PORTUGAL, 2016, p. 42).

A ideia de que o sujeito pós-prometeico é um designer, um articulador criativo, conduz-nos a retomar a possível correlação, na contemporaneidade, entre Hermes e Prometeu. Antes, porém, é interessante notar como a ressonância prometeica, incluindo 
suas configurações "pré" e "pós", acaba se estendendo ao longo de boa parte da história do pensamento ocidental. Talvez seja possível, com efeito, associar os três aspectos prometeicos (fogo, antecipação e ladrão) aos três estágios identificados por Portugal: a noção de antecipação está ligada à liberdade pré-prometeica, pois a esfera metafísica funciona como um caução e uma garantia para nossas ações; o fogo, enquanto bem precioso, remete à ideia prometeica de livre-arbítrio, como necessidade e bem a ser duramente conquistado; por fim, o ladrão caracteriza o sujeito pós-prometeico, que é capaz de trair e burlar suas próprias "raízes" prometeicas (o que, no vocabulário de Durand, remeteria a um Prometeu destituído de alguns de seus mitemas).

Temos aqui uma pista significativa: o mitema do "roubo", como vimos, aparece tanto em Prometeu quanto, embora de modo mais sutil, em Hermes (que rouba o gado de Apolo). Ainda que a conotação do roubo seja, por certo, bem diferente entre os dois mitos - o roubo prometeico é sacrificante e culmina em traição aos deuses, enquanto o hermesiano faz alusão à destreza de seus "truques" -, o que se sobressai como denominador comum são ideias como astúcia, insídia, artifício, simulação. Trata-se da figura do artifex, o artista ou artífice, mas também o burlão, especialista do artifício, do artificial e inclusive da artilharia. Tal conotação, não obstante, é explorada por Vilém Flusser para descrever o lugar que a palavra design ocupa no discurso contemporâneo:

No fundo, o que une os termos supracitados [arte, artifício, design] consiste no facto de todos se referirem (entre outras coisas) a conceitos como embuste e cilada. A nova forma de cultura a que o design deveria desbravar caminho é uma cultura consciente do facto de ser falaz (FLUSSER, 2010, p. 11).

Com isso, podemos tecer, enfim, alguns comentários sobre o espaço aberto pelo design, que se encontra dividido e partilhado por Hermes e Prometeu. Parece inegável que, ao longo do século XX até hoje, ocorreram transformações profundas no âmbito sociocultural, mas seria no mínimo precipitado pensar em esgotamento ou inversão total da lógica prometeica. As vanguardas artísticas e literárias, por exemplo, das quais Durand (1992) extrai sinais do abatimento prometeico, serviram em certa medida mais como continuidade e menos como ruptura dos modelos normativos que as precediam, pois ainda se pautavam num pressuposto implícito: a garantia (ou sua impossibilidade) de referiremse a algo verdadeiro (CRARY, 2013). Podemos pensar, em contrapartida, no atual panorama midiático do jornalismo, que não se propõe a nos descrever meramente os "fatos" - se é que um dia já o fez -, mas a nos apresentar acontecimentos já vestidos de todos os comentários, 
interpretações e previsões possíveis. Não se trata de manipular os fatos, tampouco de imparcialidade, e sim de evidenciá-los enquanto interpretações.

$\mathrm{O}$ que as vanguardas do século XX e o atual panorama midiático do jornalismo têm em comum é um enfrentamento do problema geral da "verdade" e da capacidade ao mesmo tempo unificadora e desintegradora das interpretações. Não é que tudo tenha se tornado mera questão de "pontos de vista", e sim, o que é bem diferente, que tomamos consciência justamente do poder ao mesmo tempo prometeico e hermesiano das interpretações: elas ganham força não só porque acreditamos nelas, mas especialmente na medida em que, de algum modo, elas ressoam e se transformam (inclusive no seu oposto).

Por isso, no momento presente, tentar diagnosticar a falência de certos mitos ou a hegemonia de outros é uma tarefa que, se ainda faz algum sentido, só consegue se manter a curto prazo. Ao mesmo tempo, contudo, não é insignificante o fato de que se proliferam tantas visões reducionistas enquanto o conhecimento se torna múltiplo; que ideais desgastados como o de "orgulho nacional" recebam tantas roupagens e slogans, enquanto a pluralidade das diferenças culturais, étnicas e comportamentais é cada vez mais reconhecida, valorizada e reivindicada no âmbito das legitimidades sociopolíticas; que tantos indivíduos insistam em crer e reproduzir o imperativo ascético do trabalho que "dignifica o homem", enquanto são poucos os que conseguem "dignificar" o trabalho que fazem (sem dizer que não é raro não haver trabalho para todos).

É salutar, nesse sentido, o modo como Prometeu exigiu e continua a exigir que os indivíduos se mantenham exclusivamente concentrados na organização disciplinar do trabalho, da educação e do lazer, como condição necessária para uma vida livre, criativa, digna e bem-sucedida. Não é por caso que nossas vidas sejam cada vez mais permeadas pela dispersão e pelo dispêndio, seja no viés dionisíaco ou no viés das enfermidades depressivas: eis o produto de uma densa e poderosa moral prometeica (ou ascética, no vocabulário nietzscheano). Também não é alheio a tal contexto o fato de que a face hermesiana volte a florescer, isto é, por meio de sua relação recíproca com as normas e práticas prometeicas que não cessam de vigorar. De um lado, as novas práticas prometeicas não se pautam tanto na necessidade de fazer valer algum princípio qualquer, mas sobremaneira nas estratégias pelas quais os indivíduos, já destituídos de alicerces seguros, se isolam, se separam e cultivam suas crenças e pontos de vista. De outro, as formas de hibridização, bricolagem e afirmação das diferenças não são exclusiva e essencialmente hermesianas, pois nunca 
deixam de expressar direta ou indiretamente outras matrizes míticas, tais como as de Dioniso, Apolo, Édipo, Perseu, Narciso e, claro, Prometeu.

Em todo caso, o que parece ganhar destaque, como já assinalamos, é o mitema do artifex, que entrelaça Hermes e Prometeu e se expressa pelo design. Se é verdade que o mundo contemporâneo propicia o triunfo do design - portanto do que é artificioso, astuto, disfarçado -, parece-nos mais sensato e proveitoso compreender a abrangência interpretativa desse "solo", juntamente com a pluralidade dos modos de existir que nele florescem, do que se preocupar ou se contentar com rotulações hiperbólicas - crise do conhecimento, sociedade da informação, hipermodernidade etc. Trata-se de reconhecer que dependemos do design, em seu sentido amplo, para forjar algum valor para as ocasiões, para nós mesmos e para o mundo. É nesse sentido que a ênfase mítica da trama contemporânea talvez tenha se deslocado, de fato, de Prometeu para Hermes, portanto também da transcendência para a imanência, ainda que a alcunha "pós-prometeica" se encarregue de nos advertir sobre um Prometeu sempre à espreita.

\section{Considerações finais: o lugar do design no imaginário contemporâneo}

Ao que tudo indica, o ressurgimento de Hermes só pôde efetivar-se, hoje, no interior de uma bacia semântica em que Prometeu subsiste reconfigurado, de modo que os impulsos hermesianos funcionem como uma contrapremissa: questionar a pertinência de valores "prometeicamente determinados". A normatividade prometeica, outrossim, também passou a depender em certa medida do discurso hermesiano, mesmo que o obliterando - como, por exemplo, no papel de um substituto provisório ou pragmático de um relativismo impossível de ser incorporado em determinados impasses sociais. Mas a lógica hermesiana, de modo geral, se expande na medida em que se explicita a impossibilidade de apreender por inteiro um fato (cada vez mais plural e nunca idêntico a si mesmo), bem como a força das interpretações - que embora se limitem, isoladamente, a fornecer uma leitura parcial dos fatos, demonstram, em conjunto, que nos fatos nada resta além de interpretações.

Deduzir a partir daí que tudo está se tornando mais "falso", como Baudelaire já o fazia no século XIX (e tantos pensadores ainda hoje o fazem), implica a exigência de uma contraparte "verdadeira", portanto prometeica. Bem diferente é a noção de uma "desfabulação do mundo" (ALMEIDA, 2015, p. 186-187), que sublinha uma desestabilização não do mundo, mas das pretensas verdades que ainda balizam nossa relação com o mundo e que, no entanto, explicitam-se como ficções: 
[...] todas as narrativas, discursos, instituições e boas intenções perdem o estatuto de verdade e se proliferam como ficções às quais aderimos sem crença. 0 mundo desfabulado mostra-se nu, sem duplo, sem transcendência, sem finalidade ou necessidade. (ALMEIDA, 2015, p. 187).

Ademais, a proeminência que conferimos ao design mediante as linhas de força prometeicas e hermesianas não pretende dotá-lo de nenhum privilégio ontológico (como a abordagem de Latour, contudo, parece sugerir); pelo contrário, procuramos pontuar a agência e abrangência do design na esfera cotidiana. Mais precisamente, o design aciona novas formas de aderir ao espetáculo mundano: não jogamos apenas com palavras ou ideias, mas com ícones, fotografias, vídeos, estilos, representações, de tal forma que o horizonte hermesiano se abre à medida que as coisas que nos cercam (imagens, objetos, lugares e pessoas) se coordenam, se conectam, se compõem:

[...] design perfaz um ritual diário de recortar, assimilar, organizar dadas mediações de acordo com nossos gostos e com cada ocasião. [...] não se trata tanto de expressar uma "visão de mundo", mas antes de fazer diferentes modos de olhar expressarem-se uns pelos outros, num processo que é sempre ambíguo porque procede por símbolos, por simulacros, por formas que não têm significado senão na própria rede de relações a que se ligam. Insistindo neste caráter simbólico, processual e hermenêutico, podemos enfim compreender o design como articulação simbólica: uma (re)tradução constante, por meio da forma, que abre o mundo para a pluralidade das interpretações [...] (BECCARI, 2016, p. 235-236).

Posto isso, cabe-nos ainda observar que, com a atual intensidade de circulação e segmentação de concepções, gostos e estilos, o que se vê mais nitidamente em disputa no palco contemporâneo é a polarização prometeica contra a diplomacia hermesiana. De um lado, condutas reativas, excessivas e controversas são replicadas de modo a incrustar o acirramento das convivências. De outro, discursos artísticos, de entretenimento e dos mass media não escapam da influência de uma nova sensibilidade para com os conflitos, as minorias, as diferenças. De um lado a outro, o design põe em relevo nossas afeições e rejeições, nosso vocabulário, nossos gestos, nossas referências. Não é que, reiteramos, os imperativos prometeicos tenham se apagado; eles se abriram ao jogo hermesiano pelo qual o indivíduo trafega na superfície dos valores, aderindo-os ou rechaçando-os - uma abertura ao "blefe", segundo Louis Kodo:

[...] se a coisa abriu-se embaixo e o fascínio pelo blefe superou o reflexo de toda tradição, é porque a coisa abriu-se em cima. Como? Pela falência. A igreja faliu - quanto ao domínio da fé -; a justiça faliu - quanto à sua representação -; o valor aristocrata/burguês faliu - porque agora pertence a todos -; a cidade faliu - como ideia de uma coexistência pacífica. E se 
tudo faliu, é porque tudo apareceu, é porque a sua aura deixou-se sob o seu próprio blefe [...] (KODO, 2001, p. 41).

Eis o truque, a artimanha simultaneamente prometeica e hermesiana que nos atravessa e se intensifica nos mínimos gestos, no espetáculo fugaz de julgar e ser julgado, no impasse entre dizer o que se espera escutar e ter que ouvir o que não se deseja ouvir. Esperamos, assim, ter apontado um caminho para pensar a coexistência simultânea de linhas de força aparentemente opostas que, porém, se interpenetram, passando ao largo das distinções mecânicas e desgastadas entre sólidos e líquidos, vazios e abundâncias, transparências e opacidades etc. Os indivíduos contemporâneos continuam em movimento e, portanto, desancorados. De resto, a corrida prometeica avança desenfreada em busca de lucro, poder, controle e produtividade, numa lógica que impregna a voz hermesiana, sem, contudo, enclausurá-la.

\section{Referências}

ALMEIDA, Rogério de. 0 criador de mitos: imaginário e educação em Fernando Pessoa. São Paulo: EDUC, 2011.

ALMEIDA, Rogério de. As máscaras de Hermes: uma mitanálise do pós-moderno. In: ARAÚJO, Alberto Filipe; GOMES, Eunice Simões Lins; ALMEIDA, Rogério de. 0 mito revivido: a mitanálise como método de investigação do imaginário. São Paulo: Képos, 2014, p. 55-78.

ALMEIDA, Rogério de. 0 mundo, os homens e suas obras: filosofia trágica e pedagogia da escolha. Tese (Livre-Docência em Filosofia da Educação). Faculdade de Educação da Universidade de São Paulo, 2015.

ARAÚJO, Alberto Filipe; GOMES, Eunice Simões Lins; ALMEIDA, Rogério de. 0 mito revivido: a mitanálise como método de investigação do imaginário. São Paulo: Képos, 2014.

ARAÚJO, Alberto Filipe. As lições de Pinóquio: estou farto de ser um boneco!, com Joaquim Machado de Araújo e José Augusto Ribeiro. Curitiba: CRV, 2012.

BECCARI, Marcos. Articulações simbólicas: uma nova filosofia do design. Teresópolis: 2ab, 2016.

BLOOR, David. Conhecimento e imaginário social. São Paulo: Editora Unesp, 2009. 
BRANDÃO, Junito de Souza. Mitologia grega. Petrópolis: Vozes, 1986. v. 1.

BRANDÃO, Junito de Souza. Dicionário mítico-etimológico da mitologia grega.

Petrópolis: Vozes, 1992. v. 2.

CARLYLE, Thomas. Signs of the times. In: SYMONS, Julian (org.), Carlyle: Selected works, reminiscences and letters. Cambridge: Harvard University Press, 1970.

CRARY, Jonathan. Suspensões da percepção: atenção, espetáculo e cultura moderna. São Paulo: Cosac Naify, 2013.

DABEZIES, André. Fausto. In: BRUNEL, Pierre (org.). Dicionário de mitos literários. Rio de Janeiro: José Olympio, 1998.

DOUGHERTY, Carol. Prometheus. Abingdon: Routledge/Taylor and Francis, 2006.

DURAND, Gilbert. Science de l'homme et tradition. Paris: Berg International, 1979.

DURAND, Gilbert. Mito e sociedade: a mitanálise e a sociedade das profundezas. Lisboa: A Regra do Jogo, 1983.

DURAND, Gilbert. Figures mythiques et visages de L'oeuvre: de la mythocritique à la mythanalyse. Paris: Dunod, 1992.

DURAND, Gilbert. Introduction à la mythodologie: mythes et sociétés. Paris: Albin Michel, 1996.

DURAND, Gilbert. As estruturas antropológicas do imaginário. São Paulo: Martins Fontes, 1997.

DURAND, Gilbert. Campos do imaginário. Lisboa: Instituto Piaget, 1998.

DURAND, Gilbert. 0 imaginário: ensaio acerca das ciências e da filosofia da imagem. Rio de Janeiro: Difel, 2010.

ÉSQUILO; SÓFOCLES; EURÍPEDES. Teatro grego. Rio de Janeiro: W. M. Jackson, 1953.

FERREIRA-SANTOS, Marcos; ALMEIDA, Rogério de. Aproximações ao imaginário: bússola de investigação poética. São Paulo: Képos, 2012.

FLUSSER, Vilém. 0 universo das imagens técnicas: elogio da superficialidade. São Paulo: Annablume, 2008.

FLUSSER, Vilém. Uma filosofia do design: a forma das coisas. Lisboa: Relógio D'Água Editores, 2010. 
GOETHE, Johann Wolfgang. Poemas: antologia. Coimbra: Centelha, 1979.

GROPIUS, Walter. Bauhaus: novarquitetura. São Paulo: Perspectiva, 2004.

HALL, Stuart. A identidade cultural na pós-modernidade. São Paulo: DP\&A, 2000.

HESÍODO. Teogonia: a origem dos deuses. São Paulo: Massao Oho-Roswitha Kempf, 1981.

KODO, Louis. Blefe: o gozo pós-moderno. São Paulo: Zouk, 2001.

LATOUR, Bruno. Um Prometeu cauteloso? Alguns passos rumo a uma filosofia do design (com especial atenção a Peter Slotedijk). Agitprop: revista brasileira de design, São Paulo, v. 6, n. 58, jul./ago. 2014.

MAFFESOLI, Michel. A sombra de Dioniso. São Paulo: Zouk, 2005.

MILL, John Stuart. A liberdade/utilitarismo. São Paulo: Martins Fontes, 2000.

NIETZSCHE, Friedrich. Além do bem e do mal. São Paulo: Companhia das Letras, 2005.

NIETZSCHE, Friedrich. 0 nascimento da tragédia ou helenismo e pessimismo. São Paulo: Companhia das Letras, 2007.

PORTUGAL, Daniel Bittencourt. Do sujeito como legislador/artista ao sujeito como designer: liberdade e criatividade em uma teoria pós-prometeica da ação. Revista Trágica: estudos de filosofia da imanência, Rio de Janeiro, v. 9, n. 3, p. 27-43, 2016.

REALE, Giovanni. 0 saber dos antigos: Terapia para os tempos atuais. São Paulo: Edições Loyola, 2002.

RICOEUR, Paul. Hermenêutica e ideologias. Petrópolis: Vozes, 2008.

SANTOS, Alcides Cardoso dos. Visões de William Blake: imagens e palavras em Jerusalém a Emanação do Gigante Albion. Campinas: Editora da Unicamp, 2009.

SMITH, Adam. A riqueza das nações: investigação sobre sua natureza e suas causas. São Paulo: Abril Cultural, 1983.

SULLIVAN, Louis. Louis Sullivan: The Public Papers. Chicago: Chicago University Press, 1988.

WILLIAMS, Bernard. Shame and necessity. Berkeley: University of California Press, 2008. 


\title{
Prometheus against Hermes: the place of design in the contemporary imaginary
}

\begin{abstract}
This article proposes a reflection on the contemporary imaginary, taking the design as a central vector and two mythical figures, Hermes and Prometeu, as main coordinates. First, we make some considerations about the theoretical bases that support the approach proposed here, and then we indicate the way in which the figures of Prometeu and Hermes lead much of the sociocultural dynamics. Next, we analyze the postPromethean paradigm that Bruno Latour identifies from five connotations of the term design. We conclude, finally, that the myths of Hermes and Prometheus are implied in each other and that the design expresses, in the contemporary imaginary, this correlation.
\end{abstract}

\section{Keywords}

Contemporary imaginary. Prometheus. Hermes. Design.

Recebido 15/03/2017

Aceito 20/06/2017 